\title{
S.B.Ü Haseki Eğitim Araştırma Hastanesi Yenidoğan Kliniği Dört Yıllık Yenidoğan Işitme Taraması Sonuçları
}

\author{
Evaluation of Newborn Hearing Screening Results in a Period of \\ Four Years Newborn Hearing Screening Results
}

\author{
Emel ATAOĞLU ${ }^{1}$, Demet OĞUZ ${ }^{1}$, Kamuran MUTLUAY ${ }^{2}$, Murat ELEVLI ${ }^{3}$ \\ 1. Uz. Dr, Sağlık Bilimleri Üniversitesi Haseki Eğitim Araştırma Hastanesi, Yenidoğan Yoğun Bakım Ünitesi, İstanbul \\ 2. Uz. Dr, Sağllk Bilimleri Üniversitesi Haseki Ĕ̆itim Araştırma Hastanesi, Çocuk Sağlı̆̆ ve Hastalıkları Kliniği, İstanbul \\ 3. Prof. Dr, Sağlık Bilimleri Üniversitesi Haseki Eğitim Araștırma Hastanesi, Çocuk Sağlı̆̆ı ve Hastalıkları Kliniği, İstanbul
}

\section{$\ddot{O Z E T}$}

Amaç: Konjenital işitme kaybı, yenidoğan bebeklerde görülen en yaygın doğumsal bozukluktur. Yenidoğanlarda ișitme taramasl, işitme kaybı olan bebeklerin mümkün olduğunca erken tanı almasını amaçlar. Bu çalışmamızda hastanemizde dört yıllık sürede, 8451 yenidoğan bebeğe yapılan ișitme taraması sonuçlarının değerlendirilmesi ve sunulması amaçlanmıştır.

Gereçler ve Yöntem: Çalı̧̧mamıza, 1 Ocak 2013-31 Aralık 2016 tarihleri arasinda hastanemizde doğan ve risk faktörü olup başka hastaneden işitme taraması için sevk edilmiş bebekler alınds. Testler bebek taburcu olmadan odyometrist tarafindan otoakustik emisyon (TOAE, transient evoked autoacoustic emissions) yöntemi ile yapıld. İkinci basamakta; iki kere TOAE testini geçemeyen veva risk faktörü olan veya risk faktörü olduğu için başka hastaneden sevk edilen bebeklere TABR yapıldı. İsitme taraması yapılan bebeklerin kayıtları ve sonuçlar değerlendirildi.

Bulgular: Dört yıllık sürede 8451 bebeğe işitme taramast yapılmıştır. Bunların 4968'ine birinci basamak işitme testi uygulanirken, risk faktörleri nedeniyle veya dis merkezlerden 2 kez TOAE testinden kaldı̆̆ için gönderilen 4007 bebeğe TABR yapıldl. TOAE testi uygulanan 4968 bebekten 4134 '̈̈ $(\% 83,2)$ birinci basamakta geçti. Ikkinci test için çağrılan $834(\% 16,7)$ bebekten kontrole gelen $524(\% 10,5)$ bebeğin tamamı testi geçti, $310(\% 6,2)$ bebek ise kontrole gelmedi. TABR testi uygulanan 4007 bebekten 3652 'si $(\% 91,1)$ testi geçerken, 355'i $(\% 8,8)$ ikinci TABR testi için çăgrıldı. Yüz on $(\% 2,7)$ bebek kontrole gelmezken, kontrole gelen $245(\% 6,1)$ bebekten $98(\% 2,4)$ bebek üçüncü basamakta değerlendirilmek üzere sevk edildi. Kesin işitme kaybu olan $19(\% 0,22)$ bebek tespit edildi.

Sonuç: Işsitme taraması ile tüm yenidoğanların değerlendirilmesi, işitme kaybı olan bebeklerin mümkün olduğunca erken tanı alması amaçlanmaktadır. Issitme kaybı olan bebeklerin erken tanı ve rehabilitasyonu ile yaşlarına uygun sosyal, duygusal ve dil gelişimini să̆lamak mümkün olacaktır.

Anahtar Kelimeler: işitme taraması, konjenital işitme kaybı

\section{ABSTRACT}

Objective: Congenital hearing loss is found to be the most common congenital defect among newborns. After birth, newborn hearing screening program aims to detect congenital hearing loss as early as possible. The aim of this study was to evaluate and present our hospital's newborn hearing screening program results including 8451 babies for a period of four years.

\section{Iletişim:}

Sorumlu Yazar: Demet OĞUZ

Adres: Keresteci Aziz Sokak Funda Apt., 17A/10, Bahariye, Kadıköy, İstanbul, Türkiye

Tel: +90 (532) 2575989

E-Posta: demoguz@hotmail.com

Makale Geliş: 25.07.2018

Makale Kabul: 27.07.20.18

DOI: http://dx.doi.org/10.16948/zktipb.447801
Material and Methods: Babies who were born in our hospital's Obstetric Department between January 2013 and December 2016 and babies who were referred from other regional hospitals due to presence of a risk factor for hearing loss were included in the study. During working hours, babies were initially screened with TOAE test performed by an audiometrist before hospital discharge. Babies who failed TOAE test for 2 times and babies with risk factors or the ones referred from other hospitals were all evaluated by TABR as a secondary level screening. The results of the screening program and the records of the babies were evaluated.

Results: A total of 8451 newborns were screened for congenital hearing loss during 4 years period. With first level screening, 4986 babies were evaluated with TOAE. Four thousand and seven babies with risk factors and the ones who were referred because of failure of TOAE for 2 times, were tested with TABR. Of the 4968 babies who were screened with TOAE, 4134(83,2\%) passed the test. Of the $834(16,7 \%)$ babies who were called for the second TOAE test, 524 (10,5\%) passed the test, whereas $310(6,2 \%)$ did not comefor a control test. Only 3652 (91,1\%) babies passed the TABR test, whereas 355 (8,8\%) were called for a second TABR test. Hundred and ten $(2,7 \%)$ babies were not brought for control testing. Of the $245(6,1 \%)$ babies who were brought for second TABR test, 98 (2,4\%) of them were referred for tertiary level evaluation. Nineteen babies (0,22\%) were found to have congenital hearing loss.

Conclusion: With congenital hearing screening, the aim is to test every newborn in order to detect congenital hearing loss as early as possible after birth. Early identification and rehabilitation of the babies with congenital hearing loss will give an opportunity for optimum social, emotional and linguistic development.

Keywords: congenital hearing loss, hearing screening

\section{GİRIŞ}

Konjenital ișitme kaybı yenidoğan bebeklerde görülen en yaygın doğumsal bozukluk olarak belirtilmektedir (1). Sağlıklı yenidoğanlarda konjenital işitme kaybısıklığ $\%$ 0.1-0.6 arasında değişirken (2-4), risk faktörü varlığında bu oran \%1-3'e kadar yükselmektedir $(5,6)$. Yenidoğanlarda ișitme taraması, işitme kaybı olan bebeklerin mümkün olduğunca erken tanı almasını amaçlar. İșitme kaybının erken tanısı ile bebeklerin sosyal, duygusal, bilişsel, konuşma ve dil gelişimi sağlanabilmektedir. Amerikan Pediatri Akademisi Bebek İşitme Komitesi tüm bebeklere 3. aydan önce işitme taraması yapılmasını ve 6 . aydan itibaren uygun tedavinin başlatılmasını önermektedir (7).

Yenidoğan işitme taramalarında yaygın olarak otoakustik emisyon [EOAEs:Evoked Otoacoustic Emissions] ve işitsel beyin sapı cevabı [ABR:Auditory Brainstem Response] ölçümleri birlikte veya tek tek kullanılır. 
Ülkemizde yenidoğan işitme taraması ilk olarak Hacettepe ve Marmara Üniversitesi Tip Fakültesi Odyoloji Bölümlerinde yapılmaya başlanmıştır. İki bin yılından itibaren tarama yapilan merkezlere diğer üniversite hastaneleri ve doğumevleri eklenmiş olup ülkemizde tarama çalışmaları hız kazanmıştır. İki bin dört yılında ise tüm ülkede doğum hastanelerini kapsayan Ulusal Yenidoğan İşitme Taraması Kampanyası başlatılmıştır (8). Bizim hastanemizde de 2008 yılından beri tüm yenidoğan bebeklere işitme taramasi yapilmaktadır.

Bu çalışmamızda, hastanemizde Ocak 2013 - Aralık 2016 tarihleri arasında 8451 yenidoğan bebeğe yapılan işitme taraması sonuçlarının değerlendirilmesi ve sunulması amaçlanmıştır.

\section{GEREÇ ve YÖNTEM}

Çalışmamıza, Ocak 2013 - Aralık 2016 tarihleri arasında hastanemiz Kadın Doğum Kliniğinde doğan bebekler ve risk faktörü olup başka hastaneden sevk edilmiş olanlar alındı. İşitme taramaları, çalışma günlerinde bebek hastaneden taburcu olmadan odyometrist tarafindan otoakustik emisyon (TEOAE, transient evoked otoacoustic emissions) yöntemi ile yapıldı. Tatil günlerinde taburcu olan bebeklerin ailelerine ișitme taraması hakkında bilgi verilip, en geç 15 gün içerisinde bebeklerini işitme taraması için getirmesi söylendi.

İşitme taramaları, sadece işitme taraması yapılmak üzere seçilmiş ve dizayn edilmiş özel bir odada, odyometrist tarafindan, Accu Screen ( Madsen ) cihazı ile yapıldı. Taramalar üç basamak halinde yapilmaktadır. Birinci basamakta test sessiz ortamda, bebek annesinin kucağında sakin bir durumdayken uygulandı. Bebeğin diş kulak yoluna uygun problar yerleştirilerek, otoakustik emisyon cihazı ile 35 dB ses (klik) kulağa gönderilerek iki taraflı ölçüm yapıld1. Otoakustik emisyon cihazında otomatik olarak "geçti" sonucu alınması geçme kriteri olarak kabul edildi. Testten tek veya çift kulak kalan bebeklere bir hafta sonrasına tekrar TOAE testi için randevu verildi. İkinci kontrolde iki kulağından da geçen bebekler taramadan geçti kabul edildi. İkinci kontrolde de tek veya iki taraflı kalan bebeklere tarama ABR (ABR: Auditory Brainstem Response) için 15 gün sonrası için randevu verildi. İkinci basamakta; iki kere TOAE testini geçemeyen veya Kadın Doğum Kliniğinde doğup risk faktörü olan veya risk faktörü olduğu için başka hastaneden sevk edilen bebeklere ECHO SCREEN (Natus Medical Incorporated, San Carlos, CA, USA) cihazı ile ABR bebek derin uykuda iken yapıld1. Bebek uyutulmadan önce üç tane elektrod bebeğe yapıştırilıp bebek uyku odasına gönderildi. Bebek uyuduktan sonra cihaz üzerindeki kablolar uygun elektrodlara takıldı ve uygun prob ile diş kulak yolundan klik sesi verildi. Bebeğin işitmesi normalse test cihazı üzerinde işitme dalgası belirmekte ve bize "geçti" şeklinde sonuç vermektedir. Bebek testi geçemezse test cihazı üzerinde "kaldı" şeklinde sonuç çıkmaktadır. Testi geçemeyen bebekler Kulak Burun Boğaz Uzmanı tarafından muayene edildi. Muayene sonucunda dış kulak yolu ile ilgili debris ya da otit varlığında gerekli tedavi verildi. Tedavi sonrası ikinci ABR yapıldı. Bu testi geçemeyenler üçüncü basamak referans hastanelere sevkedildi. Bu retrospektif çalışma S.B.Ü Haseki Eğitim Araştırma Hastanesi Etik Kurul'unda değerlendirilmiş ve 31.05.2018 tarihli 478 nolu karara göre etik kurul kararının gerekli olmadığ 1 kanaatine varılmıştır.

\section{BULGULAR}

Ocak 2013 - Aralık 2016 tarihleri arasında hastanemizde toplam 8451 bebeğe işitme taramas1 yapılmıştır. Bunların 4968'ine birinci basamak işitme testi uygulanırken, risk faktörleri nedeniyle veya dış merkezlerden $2 \mathrm{kez}$ TOAE testinden kaldığ için gönderilen toplam 4007 bebeğe de TABR yapıldı. TOAE testi uygulanan 4968 bebekten $4134(\% 83,2)$ bebek birinci basamakta geçti. İkinci TOAE testi için çağrılan $834(\% 16,7)$ bebekten kontrole gelen $524(\% 10,5)$ bebeğin tamamı testi geçti, $310(\% 6,2)$ bebek ise kontrole gelmedi (SSekil 1). ABR testi uygulanan 4007 bebekten $3652(\% 91,1)$ 'i testi geçerken $355(\% 8,8)$ 'u ikinci ABR testi için çağrıldı. Yüz on $(\% 2,7)$ bebek kontrole gelmezken, kontrole gelen $245(\% 6,1)$ bebekten $98(\% 2,4)$ bebek üçüncü basamakta değerlendirilmek üzere sevk edildi. Kesin işitme kayb1 olan $19(\% 0,22)$ bebek tespit edildi (Şekil 1).

TABR testi yapılan bebeklerin risk faktörlerinin başında yoğun bakımda yatmış olmak, hiperbilirubinemi ve fototerapi almış olmak, erken doğum ve işitme engelli akraba varlığ 1 gelmekteydi. Risk faktörü olmadan, iki kez TOAE'den kaldığı için TABR yapılan 216 bebek vard1 (Tablo 1).

Tablo 1: TABR yapılan bebeklerdeki risk faktörleri.

\begin{tabular}{|l|c|}
\hline \multicolumn{1}{|c|}{ Risk faktörü } & $n(\%)$ \\
\hline Yoğun bakım yatışı & $1453(\% 36,2)$ \\
\hline Hiperbilirübinemi+Fototerapi & $1385(\% 34,5)$ \\
\hline Erken doğum & $695(\% 17,3)$ \\
\hline İşitme engelli akraba & $611(\% 15,2)$ \\
\hline Düşük doğum tartısı & $126(\% 2,5)$ \\
\hline Vakumla doğum & $29(\% 0,6)$ \\
\hline Diş kulak yolu anomalisi & $27(\% 0,6)$ \\
\hline Down sendromu & $24(\% 0,5)$ \\
\hline Yarık damak & $19(\% 0,4)$ \\
\hline Hamilelikle ilgili sorunlar (ateş, enfeksiyon vb) & $7(\% 0.17)$ \\
\hline Turner Sendromu & $1(\% 0.02)$ \\
\hline Konjenital CMV enfeksiyonu & $1(\% 0.02)$ \\
\hline $\begin{array}{l}\text { Risk faktörü olmayıp iki kez TOAE’den kaldığı } \\
\text { için diş merkezden gelen bebek }\end{array}$ & $216(\% 5,39)$ \\
\hline
\end{tabular}

Tablo 2: Üçüncü basamak merkeze sevkedilen 98 bebekteki risk faktörleri.

\begin{tabular}{|l|l|}
\hline Risk faktörü & \multicolumn{1}{|c|}{$\mathbf{n}(\mathbf{\%})$} \\
\hline Yoğun bakım yatışı & $23(\% 23,4)$ \\
\hline Erken doğum & $20(\% 20,4)$ \\
\hline Hiperbilirübinemi+Fototerapi & $14(\% 14,2)$ \\
\hline İşitme engelli akraba & $14(\% 14,2)$ \\
\hline Yarık damak & $4(\% 4)$ \\
\hline Down sendromu & $3(\% 3)$ \\
\hline Risk faktörü olmayıp iki kez TABR'den kalan bebek & $40(\% 40,8)$ \\
\hline
\end{tabular}




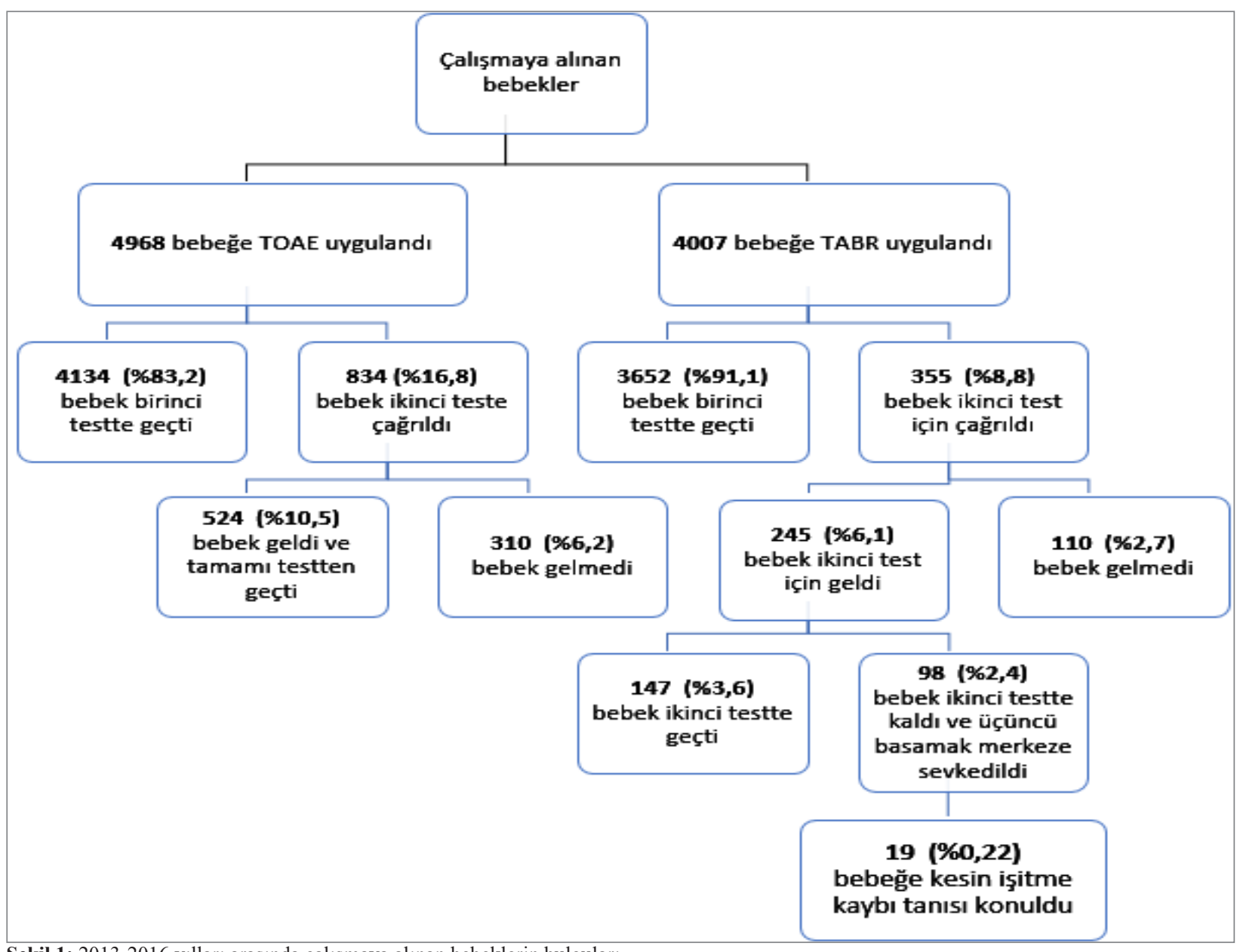

Şekil 1: 2013-2016 yılları arasında çalışmaya alınan bebeklerin bulguları.

İki kez TABR'den geçemeyip üçüncü basamak merkeze sevkedilen 98 bebeğin başlıca risk faktörlerini ise yoğun bakımdayatmak, erken doğum, hiperbilirubinemi ve işitme engelli akraba varlığı olarak bulduk.

Üçüncü basamak merkeze sevk olanların \%40,8'i $(n=40)$ hiçbir risk faktörü olmaksızın iki kez TABR'den geçememiş olan bebeklerdi (Tablo 2). Kesin işitme kaybı saptadığımız 19 bebeğin ise yarısından fazlasında $(\% 57,8)$ hiçbir risk faktörü bulunmamaktaydı (Tablo 3).

\section{TARTIŞMA}

İşitme kaybı bin canlı doğumda 1-3 insidans ile yenidoğan bebeklerde en yaygın görülen doğumsal bozukluktur (3). Bebeklerde uygun gelişim basamaklarının sağlanabilmesi için konjenital işitme kayıplarının erken tanı ve rehabilitasyonu büyük önem taşımaktadır $(9,10)$. Konjenital işitme kaybının $30 \mathrm{~dB}$ 'den daha fazla olduğu durumlarda bebeğin sadece normal konuşma ve lisan gelişimi etkilenmekle kalmaz, kognitif ve davranışsal gelişimi deetkilenir $(2,11,12)$. Bu nedenle yenidoğanda işitme taraması; işitme kaybı olan bebeklerin mümkün olduğunca erken tanı almasını amaçlar. İşitme taramasında amaç bebek 3 aylık olmadan önce işitme kaybı tanısinın konulması ve altınciaydan önce tedaviye başlanmasıdır $(8,9)$. Etkili bir tarama programının hedefi yenidoğanların minimum \%95'ini taramak ve \%100'ünü hedeflemek olmalıdır. Yalanc1 pozitiflik oran $1<\% 3$, odyolojik sevk oranı $<\% 4$ ve yalancı negatiflik oranı sifir olmalıdır (13).
Tablo 3: Kesin ișitme kaybı tanısı konan 19 bebekteki risk faktörleri.

\begin{tabular}{|l|l|}
\hline \multicolumn{1}{|c|}{ Risk faktörü } & \multicolumn{1}{c|}{ n (\%) } \\
\hline Risk faktörü yok & $11(\% 57,8)$ \\
\hline Erken doğum & $3(\% 15,7)$ \\
\hline İşitme engelli akraba & $3(\% 15,7)$ \\
\hline Hiperbilirübinemi+Fototerapi & $2(\% 10,5)$ \\
\hline
\end{tabular}

İşitme kaybı için literatürde pek çok risk faktörü tanımlanmıştır. Sensöri-nöral işitme kaybı vakalarının \%50'nde bu risk faktörleri saptanırken, diğer $\% 50$ 'nde herhangi bir risk faktörü bulunmamaktadır. Bizim çalışmamızda kesin işitme kaybı tanısı koyduğumuz 19 bebeğin 11'inde hiçbir risk faktörü mevcut değildi. $\mathrm{Bu}$ durum sadece riskli bebeklerin değil tüm yenidoğanların taranmasının ne denli önemli olduğunun bir göstergesidir. İşitme tarama programları önceleri riskli bebeklere yapılırken, günümüzde tüm bebeklere işitme taraması yapılması önerilmektedir $(14,15)$.

Hastanemizde çalışma süresince, toplam 8451 bebeğe işitme taraması yapılmış ve bu bebeklerin $\% 0,22$ 'sinde işitme kaybı saptanmıştır. Bu oran literatürde bildirilen değerlerle uyumludur. Ülkemizde yapılan diğer çalışmaları incelediğimizde, Genç ve ark. (4), çalışmalarında işitme kaybı oranını \%0.2 olarak bildirmişlerdir. Çelik ve ark. (6), Ankara Zekai Tahir Burak Hastanesi'nde geniş bir vaka serisi ile yaptıkları çalışmada işitme kaybı saptanan olgu sıklığının \%0.27 bulunduğunu ve bu değerin son yıllarda bildirilen değerlerden yüksek olduğunu belirtmişlerdir. 
Aynı çalışmada, Yoğun Bakımda yatan bebeklerin çalışmaya alınmasının ve izlenen bebeklerin erken doğum ve doğuştan bozukluklar gibi daha fazla risk etmenine sahip olmalarının, işitme kaybı saptanan bebek sayısını arttırmış olabileceği belirtilmektedir. Bildirilen bu değerlerin aksine, İstanbul'dan Vehapoğlu ve ark.'nın (16) çalışmasında işitme kaybı oran \%2.1 gibi yüksek bir değerde saptanmıştır. Vehapoğlu ve ark. (16) ise buldukları yüksek oranın nedenini kendi birimlerine dış sevkle gelen yüksek riskli hasta grubunun çalışmaya alınması olarak açıklamışlardır. Bu açıklamayla uyumlu biçimde, literatürde de riskli gruplarda işitme kaybı görülme sıklığının çok daha yüksek olduğu bildirilmektedir $(17,18)$.

Yapılan bir çalışmada konjenital işitme kaybı ile ilgili risk faktörleri olarak ilk 3 sırada ailede işitme kaybı, akraba evliliği ve yoğun bakımda ventilasyon desteği gelmektedir (16). Çelik ve ark.'nın (6) çalışmasında ise erken doğum, IUUBK, ototoksik ilaç kullanımı ve hiperbilirübinemi en önemli risk faktörleri olarak bildirilmiştir. Literatürde görüş birliğiyle kabul edilen risk faktörleri ise; ailede işitme kayb1 öyküsü, intrauterin enfeksiyon, kraniyofasiyal anomaliler, doğum ağırlığının $<1500$ gr olması, kan değişimi gerektiren düzeyde hiperbilirübinemi, ototoksik ilaç kullanımı, bakteryel menenjit, Apgar skoru düşüklügü, beş gün ve daha uzun süre MV desteği ve işitme kaybı ile ilgili sendromların bulgularının saptanmasıdır (19). Biz de çalışmamızda kesin işitme kaybılan 19 bebeğin 8'inde risk faktörlerini erken doğum, hiperbilirubinemi ve ailede işitme kaybı öyküsü olarak saptadık. Kesin işitme kaybı olan 14 bebeğe çift taraflı işitme cihazı, 1 bebeğe ise koklear implant takılarak rehabilitasyona başlandı. Telefonla ulaştı̆̆ımız 4 bebeğin ailesi ise işitme cihazı önerildiği halde taktırmak istemediklerini belirttiler.

Sonuç olarak işitme taraması ile tüm yenidoğan bebeklerin değerlendirilmesi ve işitme kaybı olan bebeklerin mümkün olduğunca erken tanı alması amaçlanmaktadır. İşitme kaybı olan bebeklerin erken tanı ve rehabilitasyonu sağlanırsa yaşlarına uygun sosyal, duygusal, bilişsel, konuşma ve dil gelişimini sağlamak mümkün olabilecektir.

Bu retrospektif çalışma S.B.Ü Haseki Eğitim Araştırma Hastanesi Etik Kurul'unda değerlendirilmiş ve 31.05.2018 tarihli 478 nolu kararda; Sağlık Bakanlığ1 tarafından yayınlanan Klinik Araştırmalar Hakkında Yönetmeliği'nin (19.08.2011 tarihli, 28030 sayılı Resmi Gazete) 2. Maddesinin 2. F1krasına göre, ilgili çalışma için etik kurul kararı gerekli olmadığı kanaatine varılmıştır. $\mathrm{Bu}$ nedenle retrospektif olarak yaptığımız çalışmamızda hasta onamı alınmamıştır.

\section{KAYNAKLAR}

1. Kenna MA. Neonatal hearing screening. Pediatr Clin N Am 2003; 50:301-313.

2. Hahn M, Lamprecht-Dinnesen A, Heinecke A, et al. Hearing screening in healthy newborns: feasibility of different methods with regard to test time. Int J Pediatr Otorhinolaryngol 1999; 51: 83-89.
3. Thompson DC, McPhillips H, Davis RL, Lieu TL, Homer CJ, Helfand $M$. Universal newborn hearing screening: summary of evidence. JAMA 2001; 286: 2000-2010.

4. Genç GA, Başar F, Kayıkçı ME ve ark. Hacettepe Üniversitesi yenidoğan işitme taraması bulguları. Çocuk Sağlığı ve Hastalıkları Dergisi $2005 ; 48: 119-124$

5. Nekahm D, Weichbold V, Welzl-Mueller K, Hirst-Stadlmann A. Improvement in early detection of congenital hearing impairment due to universal newborn hearing screening. Int J Pediatr Otorhinolaryngol 2001; 59: 23-8.

6. Çelik IH, Canpolat FE, Demirel G ve ark. Zekai Tahir Burak Kadın Sağlı̆̆ Eğitim ve Araştırma Hastanesi yenidoğan işitme tarama sonuçlarl ve hastaların değerlendirilmesi. Turk Ped. Arş 2014;49:13841 .

7. JCIH. Year 2000 position statement: principles and guidelines for early hearing detection and intervention programs. Joint Committee on Infant Hearing, American Academy of Audiology, American Academy of Pediatrics, American Speech-Language-Hearing Association, and Directors of Speech and Hearing Programs in State Health and Welfare Agencies. Pediatrics 2000;106: 798-817.

8. Bolat H, Bebitoglu FG, Ozbas S, Altunsu AT, Kose MR. National newborn hearing screening program in Turkey: struggles and implementations between 2004 and 2008. Int J Pediatr Otorhinolaryngol 2009; 73: 1621-3.

9. Paludetti G, Ottaviani F, Fetoni AR, Zuppa AA, Tortorolo G. Transient evokedotoacoustic emissions (TEOAEs) in new-borns: normative data. Int J Pediatr Otorhinolaryngol. 1999 Mar 15;47(3):235-41.

10. Levi H, Adelman C, Geal-Dor M, Elidan J, Eliashar R, Sichel JY, Bar-Oz B, Weinstein D, Freeman S, Sohmer H. Transient evoked otoacoustic emissions innewborns in the first 48 hours after birth. Audiology. 1997 Jul-Aug;36(4):181-6.

11. Kennedy CR, Kimm L, Dees DC, Evans PI, Hunter M, Lenton S, Thornton RD.Otoacoustic emissions and auditory brainstem responses in the newborn. Arch Dis Child. 1991 Oct;66 (10 Spec No):1124-9.

12. Jakubíková J, Kabátová Z, Závodná M. Identification of hearing loss in newborns by transient otoacoustic emissions. Int J Pediatr Otorhinolaryngol. 2003 Jan;67(1):15-8.

13. Erenberg A, Lemons J, Sia C, Trunkel D, Ziring P. Newborn and infant hearingloss: detection and intervention.American Academy of Pediatrics. Task Force onNewborn and Infant Hearing, 1998- 1999. Pediatrics. 1999 Feb;103(2):527-30.

14. Joint Committee on Infant Hearing position statement 1982. Ear Hear. 1983 Jan-Feb;4(1):3-4.

15. Joint Committee on Infant Hearing.; American Academy of Audiology.; AmericanAcademy of Pediatrics.; American Speech-Language-Hearing Association.; Directors of Speech and Hearing Programs in State Health and Welfare Agencies.. Year 2000 position statement: principles and guidelines for early hearing detection and intervention programs. Joint Committee on Infant Hearing, American Academy ofAudiology, American Academy of Pediatrics, American Speech-Language-Hearing Association, and Directors of Speech and Hearing Programs in State Health and Welfare Agencies. Pediatrics. 2000 Oct;106(4):798-817.

16. Türkmen VA, Yiğit Ö, Akkaya E, Uğur E, Kefeciler Z, Gözütok S. Istanbul Eğitim ve Araştırma Hastanesi Yenidoğan İşitme Taraması Sonuçlarımız. İstanbul Tıp Dergisi - 2013;14(3):175-180 .

17. Martin WH, Schwegler JW, Gleeson AL, Shi YB. New techniques of hearingassessment. Otolaryngol Clin North Am. 1994 Jun;27(3):487510 .

18. Morgan DE, Canalis RF. Auditory screening of infants. Otolaryngol Clin NorthAm. 1991 Apr;24(2):277-84.

19. Joint Committee on Infant Hearing. 1994 Position Statement. Otolaryngol.Head Neck Surg. 1995;113:191-196.

Bu çalışma 53. Türk Pediatri Kongresi’nde (14-18 Mayıs 2017) sözlü bildiri olarak sunulmuştur. 